\title{
Anabases
}

ANABASES Traditions et réceptions de l'Antiquité

$4 \mid 2006$

Varia

\section{En guise d'introduction...}

Geneviève Gal

\section{OpenEdition}

Journals

Édition électronique

URL : http://journals.openedition.org/anabases/2967

DOI : 10.4000/anabases.2967

ISSN : 2256-9421

\section{Éditeur}

E.R.A.S.M.E.

\section{Édition imprimée}

Date de publication : 1 octobre 2006

Pagination : 157-158

ISSN : 1774-4296

\section{Référence électronique}

Geneviève Gal, «En guise d'introduction... ». Anabases [En ligne], 4 | 2006, mis en ligne le 01 janvier

2012, consulté le 21 octobre 2019. URL : http://journals.openedition.org/anabases/2967 ; DOI

10.4000/anabases.2967 
Anabases 4 (2006), p. 157-158

\title{
LE DAREMberg-SAgLiO-PotTIER EN Ligne (ND@GR) : UN CHANTIER EN COURS
}

\author{
En guise d'introduction...
}

GENEVIÈVE GAL

Comme nous l'avions annoncé dans Anabases 3 (p. 252-258), c'est pour amorcer la mise en œuvre de la seconde phase du projet $N D @ G R$ (celle de la révision et de l'enrichissement de l'ouvrage) que nous avons organisé, Corinne Bonnet et moi-même, le 24 mars 2006, à Toulouse, une journée d'étude intitulée Les dictionnaires de l'Antiquité : le Daremberg, Saglio et Pottier hier et aujourd'hui.

Cette journée, à laquelle ont participé les trois équipes de recherche toulousaines travaillant sur l'Antiquité (UTAH, CRATA, ERASME), la Mission multimédia de l'Université du Mirail, ainsi que des invités extérieurs, a reçu le soutien de l'équipe ERASME, de la MSH Toulouse (Axe Patrimoine), de l'UfR d'Histoire, Art et Archéologie et du GDRI "Les Mondes Lettrés » coordonné par Christian Jacob.

Précisément, il s'agissait de réfléchir sur la manière d'entreprendre une étude historiographique du Dictionnaire des Antiquités de Daremberg et Saglio (connaissance des conditions d'élaboration de l'ouvrage - objectifs et moyens, de ses concepteurs et de ses contributeurs) et d'engager une évaluation historiographique et scientifique des notices en prenant pour support quelques-unes d'entre elles. Tout ceci dans la perspective de déboucher sur une véritable structuration du projet susceptible de répondre à la fois aux besoins scientifiques actuels et au nécessaire élargissement de la diffusion du savoir savant. 
Nous avons réuni ici la plupart des contributions à cette journée ; elles couvrent différents champs de réflexion et témoignent de l'intérêt suscité par notre entreprise. Nous vous laissons les découvrir avant de faire une synthèse des débats quelles ont ouverts et de présenter les conclusions auxquelles nous sommes parvenus sur la manière de poursuivre le projet.

GeneVIÈVE GaL

ERASME

Université de Toulouse II - Le Mirail

UFR d'Histoire, Arts et Archéologie

5, allées Antonio Machado

F-31058 Toulouse

c_gal@club-internet.fr 